\title{
Representação Como Operação
}

\section{Maria Paula Recena}

Professora do Departamento de Arquitetura da UFRGS, Rio Grande do Sul.

Contato: mariapaulapiazzarecena@gmail.com

\section{Daniel Dillenburg}

Mestre em Arquitetura e Urbanismo; UniRitter-Mackenzie.

Contato: dillen1980@gmail.com

\section{RESUMO}

O uso de meios digitais para a produção da representação arquitetônica — principalmente a partir dos anos 1990 — permite reposicionar a função do desenho à mão. Assim como a pintura adquire novo interesse com a afirmação da fotografia, o desenho à mão surge em novo patamar de interesse na produção arquitetônica após a difusão da computação gráfica. A argumentação se dá com base em análise de desenhos e diagramas de Daniel Libeskind para o Museu Judaico de Berlim, bem como estabelece, como ponto de referência, para esta reflexão, a produção da Cooper Union, especialmente centrada nos problemas dos 9 quadrados, do cubo e de Juan Gris.

Palavras-chave: Diagrama; Representação; Operação

\section{ABSTRACT}

The use of digital means for the production of architectural representation - mainly from the 1990s - allows us to reposition the function of drawing by hand. As the painting acquires a new interest with the statement of the photograph, the drawing by hand appears in new level of interest in the architectural production after the diffusion of the computer graphics. The argument is based on Daniel Libeskind's analysis of drawings and diagrams for the Berlin Jewish Museum, as well as establishing, as a point of reference, the Cooper Union production, especially focused on the The nine square problem, The cube problem and The Juan Gris problem.

Key-words: Diagram; Representation; Operation 


\section{Introduçáo}

Com o desenvolvimento da fotografia, e sua posterior popularização na virada do século XIX para o século XX, abre-se a possibilidade de congelar, no instantâneo, a imagem vista. Se desde Aristóteles (apud PATERSON, 2007, p.1) a visão é tida como o mais nobre dentre os cinco sentidos, a promessa de reproduzir fielmente a realidade fascina, e essa nova forma de representação da imagem vai, gradativamente, se sobrepondo aos meios pictóricos de representação da imagem como ato de visão. O que parece a morte da pintura, todavia, a liberta para as experimentaçóes que viriam a culminar no cubismo e na arte abstrata. Em que pese a importância de tais vanguardas como influência cultural e seus reflexos nas mais diversas manifestações artísticas — entre elas, a arquitetura - , interessa aqui apontar a possibilidade de alinhamento entre a mudança ocorrida na pintura após a difusão da fotografia e algo semelhante que se dá no processo de projetar a arquitetura após a difusão da computação gráfica e que tem consequências tanto na representação final do projeto quanto no objeto arquitetônico construído.

O uso de meios digitais para a produção da representação arquitetônica, o qual se dá principalmente a partir dos anos 1990, reposiciona a função do desenho à mão, que foi, desde o Renascimento, o meio por excelência da produção e representaçáo do projeto arquitetônico.

Passadas algumas décadas do uso em massa das tecnologias digitais nos meios arquitetônicos, parece seguro afirmar que, assim como a pintura adquire novo interesse com a consolidação da fotografia, o desenho à mão surge em novo patamar de interesse após a difusão da computação gráfica.
Se a pintura, livre dos macetes da mímesis acadêmica ${ }^{1}$ (Duarte, 1994, p.311), encontra novos horizontes de pesquisa numa troca em que o "motivo" - seja ele o Rei, a Rainha, a paisagem ou a natureza morta passa a ser a própria pintura, conferindo a ela um caráter epistemológico, entáo podemos pensar que o mesmo acontece com o desenho à mão, que, livre do heroísmo da representação de uma possível realidade - o edifício - , passa a transitar em um novo patamar especulativo.

Robin Evans apontava, em 1986, que, diferentemente do desenho clássico, que se apoia na realidade,

O desenho em arquitetura não é feito depois da natureza, mas antes da construção; não é tanto produzido pela reflexão sobre a realidade fora do desenho, senão como produtor de uma realidade que terminará sendo exterior a ele. Se inverte a lógica do realismo clássico, e é através dessa inversão que o desenho arquitetônico obteve um poder generativo enorme e em grande parte desconhecido: às escondidas. Pois, quando digo desconhecido, quero dizer náo reconhecido em princípios e em teoria. A hegemonia do desenho sobre o objeto arquitetônico nunca foi seriamente desafiada. $\mathrm{O}$ que se entendeu foi a distância que o separa daquilo que representa [...]. ${ }^{2}$ (EVANS, 1986, p.7, tradução nossa)

Vale esclarecer, portanto, que o caráter especulativo dos desenhos à mão não é novo. Como analogia, a própria história da arte, tomada sob o viés do ana- 
cronismo demonstrado por Didi-Huberman ${ }^{3}$, redescobre as abstraçóes de Jackson Pollock nos afrescos de Fra Angelico em San Marco (1440-1450) invocando, de certa forma, um novo horizonte para a pintura abstrata, subconsciente e anterior ao período das vanguardas do início do século $\mathrm{XX}$ às quais o expressionismo abstrato se alinha como consequência. De modo semelhante, no caso do desenho como produção arquitetônica relevante, desvendar essas manobras e trazê-las ao centro da discussão sugere caminhos ainda não trilhados.

O presente artigo busca argumentar que a produção de diagramas como esboços iniciais que permitem desenvolver um projeto arquitetônico de forma não-linear ou não-narrativa é tanto o fruto de uma maior liberdade dada ao desenho que se vê livre da obrigação virtuosa de representação de uma realidade em porvir, como é também o foco de interesse renovado na produção manual. $\mathrm{O}$ desenho não se encerra na produção manual, estendendo-se a estratégias diagramáticas que operam também por meios digitais; no entanto, o desenho produzido originalmente sem a mediação do meio digital, assume novo foco de interesse ao estar restrito ao campo operativo de projeto, já que, como foi dito antes, não está mais a serviço da representação do artefato idealizado. Tomados como testemunhos ou provas de uma produção que se realizará, finalmente, no edifício ou na cidade, os desenhos que interessam como categoria epistemológica desvendam lógicas restritas, que se oferecem à compreensão do outro apenas por meio de tais desenhos. $\mathrm{O}$ poder generativo às escondidas apontado por Evans surge, então, de forma inequívoca em desenhos que, produzidos apenas com o objetivo de testar estratégias de projeto, ficam livres para exercer claramente seu papel operativo.
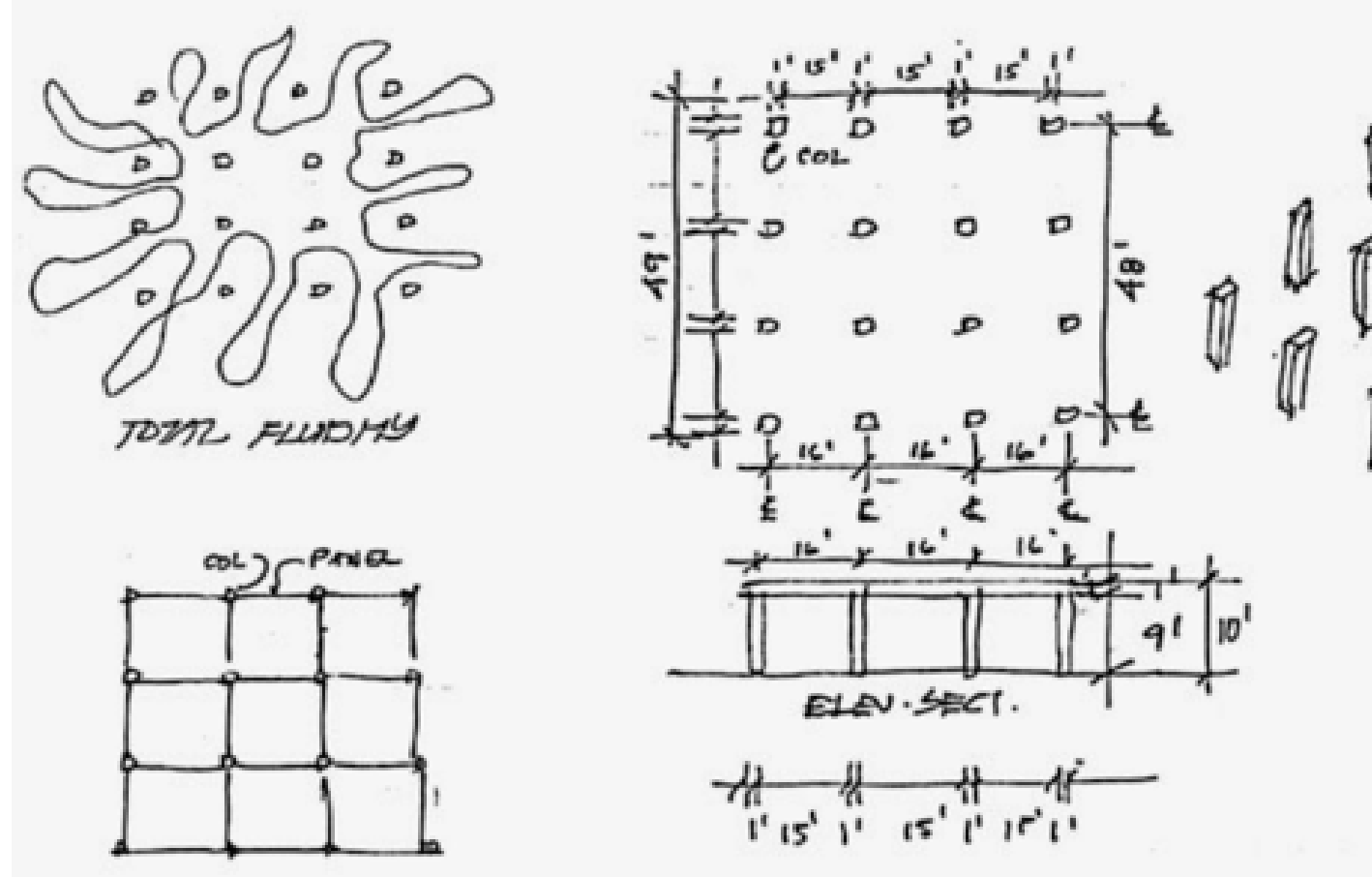

Figura 1: Nine Square Problem. 


\section{Um ponto de referência}

A experiência fundadora de John Hejduk, já em meados dos anos 1950, na Texas University, com a formulação do 'problema dos nove quadrados', estabelece um ponto de partida para a produçáo que interessa aqui analisar. Inserido em um momento caracterizado pela busca de uma certa autonomia da disciplina arquitetônica, o problema dos nove quadrados, em seu caráter utópico - já que tal autonomia é uma profecia não realizável —, talvez por isso mesmo, ainda fascina. A abstração levada ao esgotamento que o problema propóe indica estratégias projetuais diagramáticas, descoladas da representação de uma suposta realidade, mas altamente geradoras de novas operaçôes de projeto. Ao se desvincularem de uma produção realizada com base no ponto de vista humano, corporificada na perspectiva cônica, opera- çôes de projeto propostas às escondidas, como Evans aponta, são destacadas.

O problema dos nove quadrados é levado para a Cooper Union, onde encontra ressonância dentro do que podemos encarar como um viés ou uma tradição.

Trabalhando com este problema o estudante começa a descobrir e entender os elementos de arquitetura. Grade, quadro, poste, viga, painel, centro, periferia, campo, borda, linha, plano, volume, extensão, compressão, tensão, cisalhamento, etc. $\mathrm{O}$ aluno começa a investigar o significado de plano, elevação, corte e detalhes. Ele aprende a desenhar. Ele começa a compreender as relaçóes entre desenhos bidimensionais, projeçóes axonométricas, e a forma (modelo) tridi-
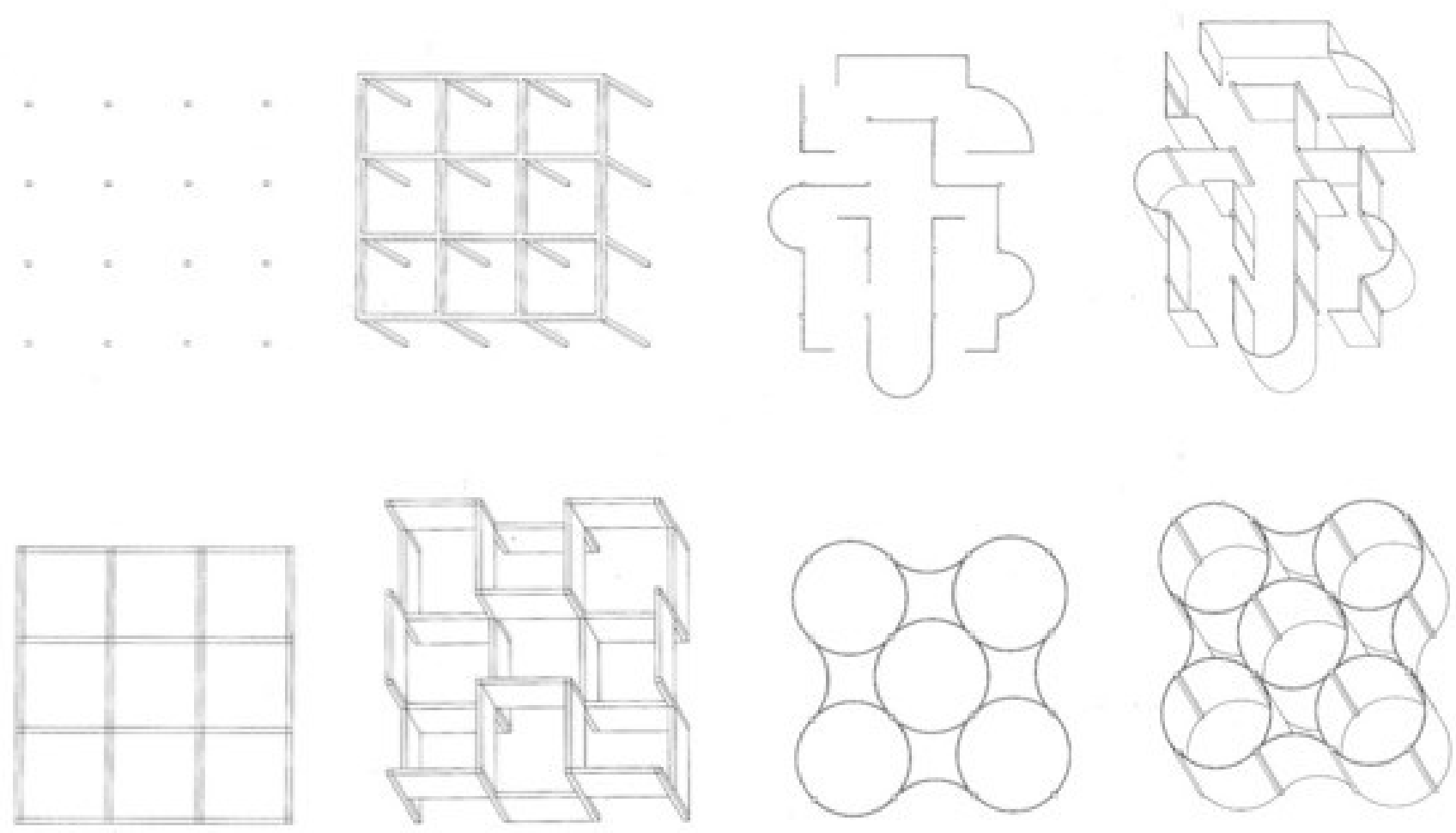

Figura 2: Nine Square Problem.

Revista online do Departamento de Arquitetura e Urbanismo da Pontifícia Universidade Católica - 

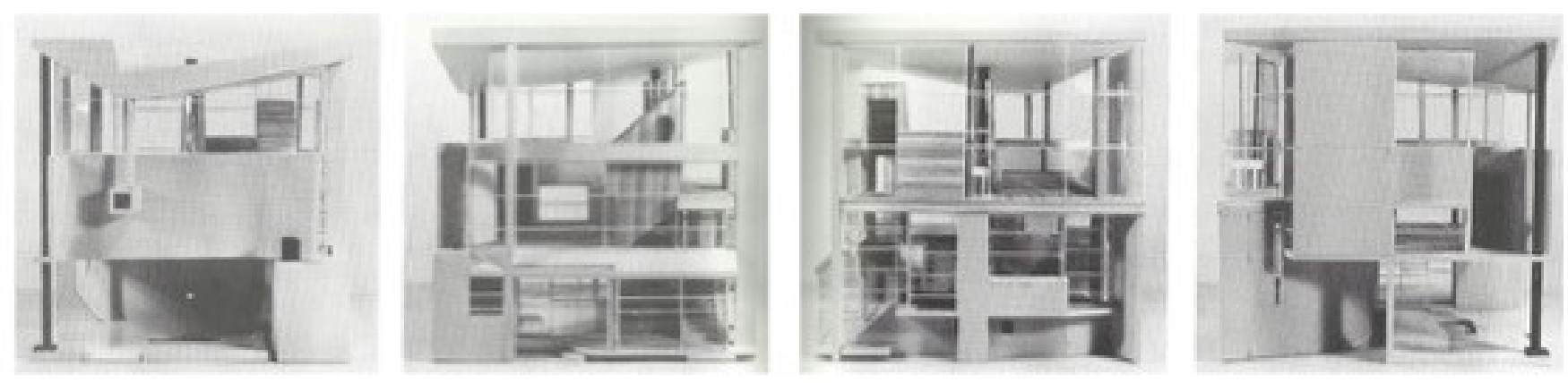

Figura 3: Residência, resultado do Problema do Cubo. Exercício de Theodore Michael Ceraldi.

Fonte: Education of na architect: a point of view. The Cooper Union School of Arts \& Architecture. New York: Monacelli Press, 1999.

mensional. O aluno estuda e desenha seu esquema em planta e em axonométrica, para buscar as implicações tridimensionais do seu modelo. Uma compreensão dos elementos é revelada — uma ideia de fabricação emerge. ${ }^{4}$ (HEJDUK, 1971, p.7, tradução nossa)

A ideia de fabricação tem sequência com o Problema do Cubo [Figura 3], em que o aluno deveria propor um programa tendo por base uma configuração ou volume inicial:

Um Problema do Cubo não é exclusivo de uma particular escola de arquitetura; é um tanto universal; o poder de permanência parece proclamar que ainda será usado por algum tempo no futuro como um problema didático. $\mathrm{O}$ interesse reside na forma como é visualizado. É típico que o arquiteto receba um programa do qual um objeto emerge; parece plausível que talvez o oposto possa ocorrer. Ou seja, dado um objeto, talvez um programa possa surgir. Esta é uma das premissas declaradas após a apresentação do Problema do Cubo. 5 (HEJDUK, 1971, p.99, tradução nossa)
Finalmente, no problema de Juan Gris, questóes propostas no cubismo são trazidas para a arquitetura, ideia claramente exposta por Rowe e Slutzky em Transparency: Literal and Phenomenal (1955), não por acaso, no período em que estavam atuando como professores na Texas University:

Frontalidade, supressão de profundidade, ordenamento do espaço, definição de fontes de luz, inclinação dos objetos para a frente, paleta restrita, redes oblíquas e retilíneas e propensôes para o desenvolvimento periférico. ${ }^{6}$ (ROWE; SLUTZKY, 1963, p.45, tradução nossa).

Com a premissa "faça um prédio no entendimento de Juan Gris", o problema de Juan Gris é considerado por Hedjuk o mais difícil:

A maioria dos alunos o rejeita, alguns se interessam por suas implicaçóes [e] alguns, usando isso como base para o movimento, produzem um trabalho. Para aqueles que escolhem esse problema, é feita uma análise muito minuciosa das ideias geradoras nas pinturas de Juan Gris e no trabalho dos cubistas 
- Picasso, Braque e Leger. O relacionamento entre as ideias e o trabalho dos arquitetos e pintores é descoberto. Uma compreensão de ligaçóes orgânicas é revelada. A busca é mais do que apenas uma análise histórica, pois o aluno produz um trabalho. Ele descobre que a declaraçáo inicial do problema o inicia no mundo da recriação e, finalmente, da criação. Isso, é claro, poderia ser a visão ilusória do professor - a realidade do aluno pode estar em outro lugar. $\mathrm{O}$ exposto depende da crença de que Juan Gris é importante para os arquitetos e para as questôes de hoje. ${ }^{7}$ (HEDJUK, 1971, p.163, tradução nossa)

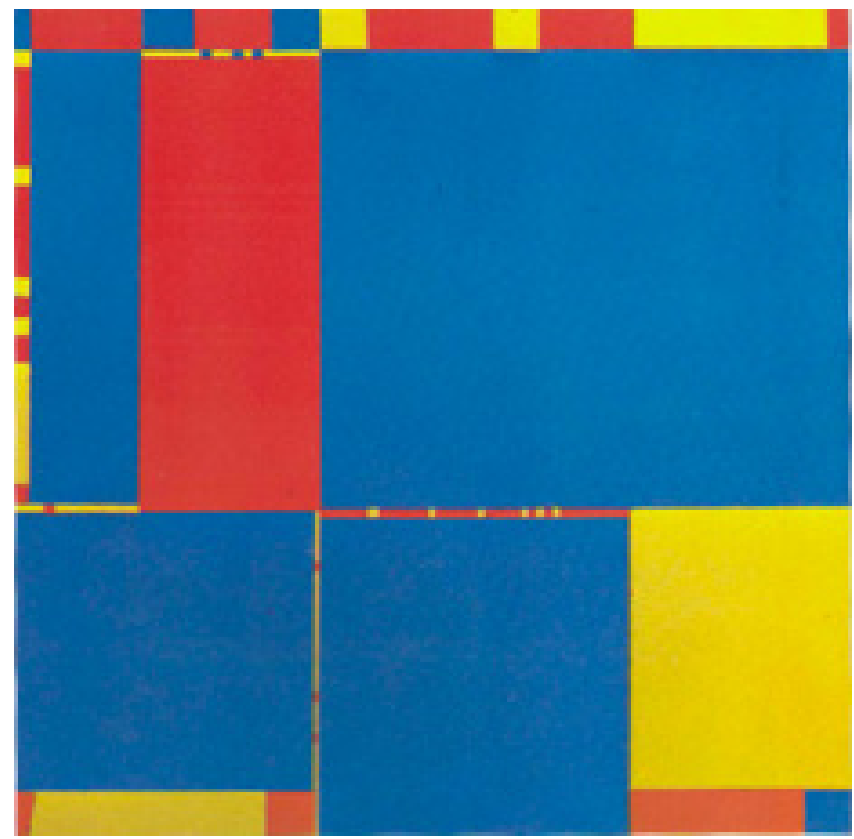

Figura 4: Desenho colorido de Daniel Libeskind.

Fonte: Education of an architect: a point of view. An exhibition by the Cooper Union School of Art \& Architecture at the Museum of Modern Art, New York City, november, 1971. p.56. (Autoria consultada em: Education of an architect: a point of view. The Cooper Union School of Arts \& Architecture. New York: Monacelli Press, 1999.).

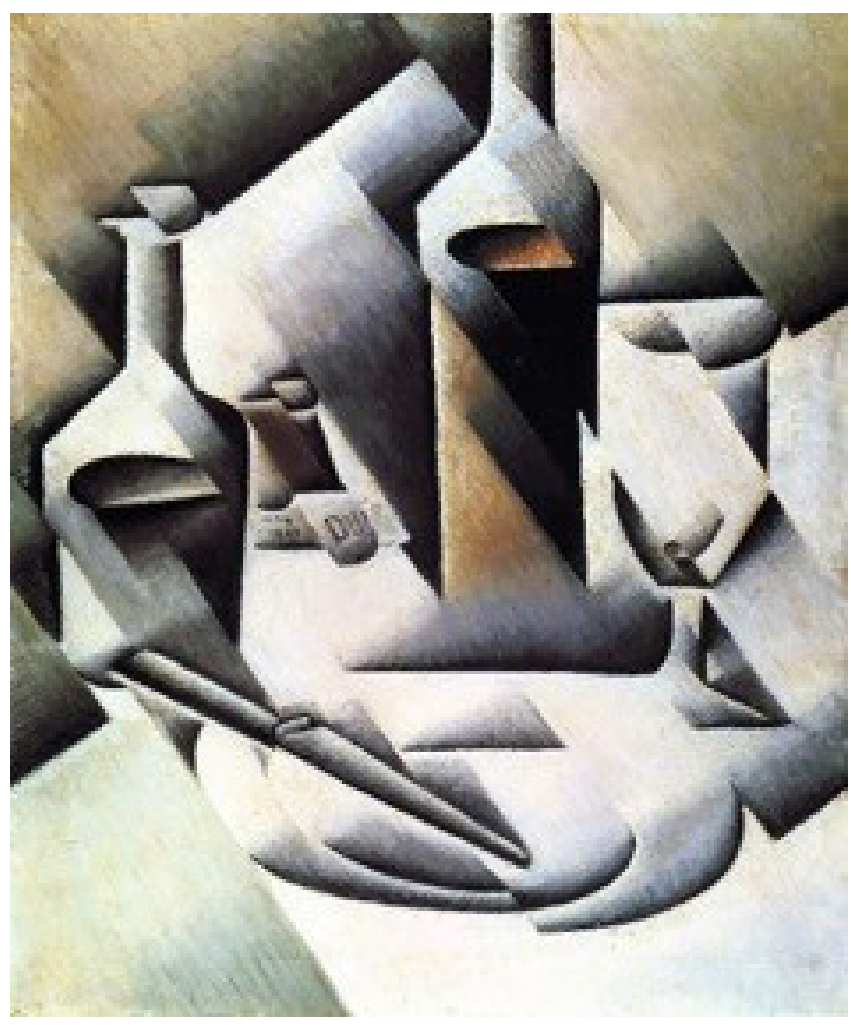

Figura 5: Bottles and Knife, de Juan Gris (1912).

Fonte: http: www.wikiart.org/em/juan-gris.

Fazer um edifício conforme as intenções de Juan Gris é quase como subverter o sistema cartesiano. Diversas camadas, objetos sobrepostos que realizam movimentos de rotaçáo em planos diferentes, colagens e geometrização são traços visíveis nos trabalhos desse artista, e aplicá-los à arquitetura, em um trabalho acadêmico, consiste em algo bem complexo. 


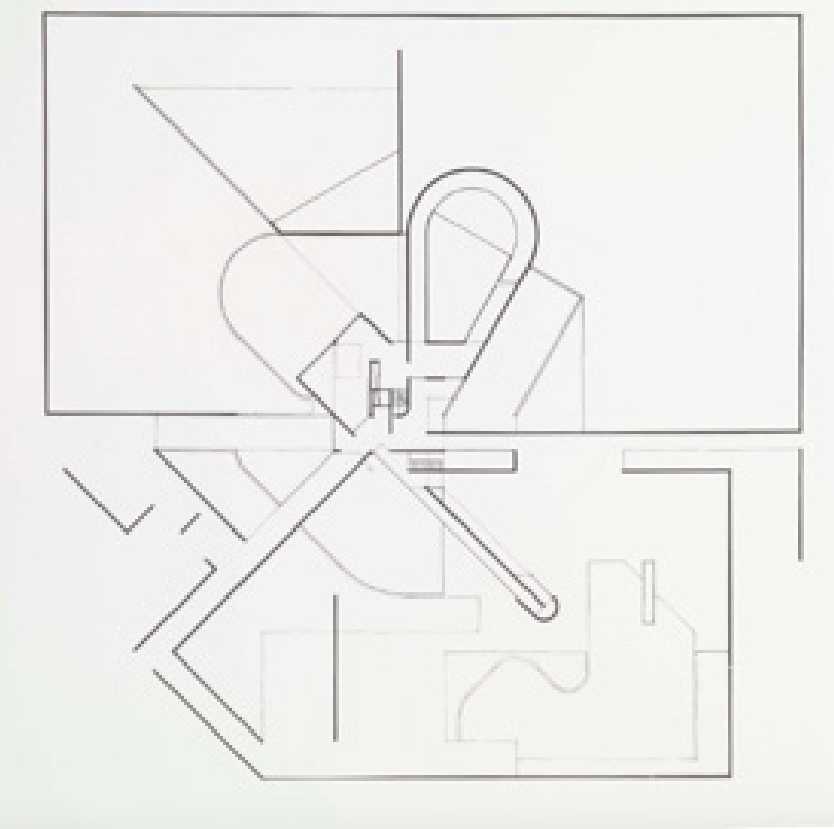

Figura 6: Residência, resultado do Problema de Juan Gris. Exercício de Carl Stein.

Fonte: Education of an architect: a point of view. An exhibition by the Cooper Union School of Art \& Architecture at the Museum of Modern Art, New York City, november, 1971. p.182.

\section{Desenhos}

Cabe examinarmos um exemplo, herança direta das experimentaçôes expostas anteriormente, que demonstra $\mathrm{o}$ argumento aqui apresentado: a posição assumida pelo desenho, livre das convençóes relativas à representação fiel da realidade. O exemplo abordado é o projeto de Daniel Libeskind, apresentado para o concurso para o Museu Judaico de Berlim:

O sítio é no novo-antigo centro de Berlim, em Lindenstrasse, ao lado do distinto Kollegienhaus, o antigo prédio Barroco do Tribunal da Prússia. Ao mesmo tempo que havia esse terreno visível atual, eu sentia que havia uma matriz invisível de conexôes, uma conexão de relações entre figuras de alemães e judeus. Mesmo que a competição tenha sido realizada antes da queda do Muro, senti que a única característica de ligação que atravessava o Oriente e o Ocidente era a relação dos alemães com os judeus. Certas pessoas, trabalhadores, escritores, compositores, artistas, cientistas e poetas formaram a ligaçáo entre a tradição judaica e a cultura alemá. Eu encontrei essa conexão, e eu tramei uma matriz irracional que originaria os emblemas de uma estrela comprimida e distorcida - estrela amarela que era táo frequentemente usada pelos judeus neste mesmo sítio. Este é o primeiro aspecto do projeto. $^{8}$ (LIBESKIND, 2011, p.71)

Essa matriz irracional e invisível de relações surge quando Libeskind resolve marcar no mapa de Berlim o endereço de algumas pessoas (tanto de judeus quanto de gentios) que admirava. Assim, conecta alguns nomes "desenhando uma linha que parte do endereço de um e vai até o endereço de outro". Por exemplo, liga o poeta do Holocausto Paul Celan ao arquiteto Mies van der Rohe. Quando traça seis nomes e cria três emparelhamentos, vai estudando as formas geradas durante esse processo e acaba descobrindo que elas "resultavam em uma Estrela de David distorcida sobre o mapa Berlim”. (LIBESKIND, 2004, p.93). [Figuras 7 e 8]

A imagem comprimida da Estrela de David implantada no mapa de Berlim é a versão definitiva, a que foi apresentada para o concurso do Museu Judaico de Berlim em 1988. Inclusive, o sítio e o prédio do Museu aparecem no vértice de um dos triângulos. 

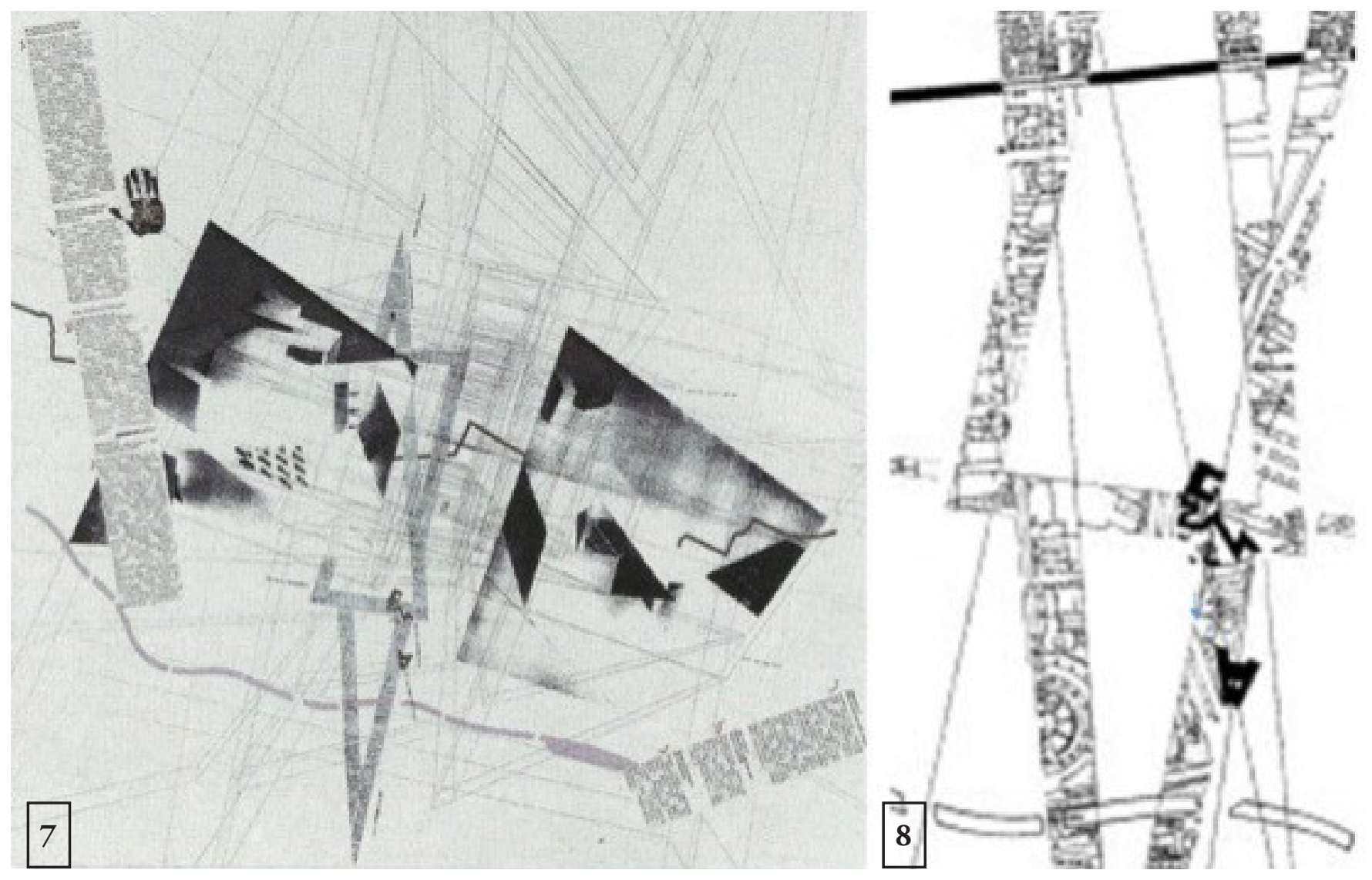

Figura 7: Estrela de David distorcida sobre o mapa de Berlim.

Figura 8: Museu Judaico ocupando um dos vértices da Estrela.

Essa relação abstrata se torna menos arbitrária ao compreendermos o diagrama inicial de Libeskind, em que a linha da história judaica aponta para baixo, para o passado, enquanto o vetor da história alemã se direciona para o futuro. (Dogan; Nersessian, 2012). No canto inferior esquerdo da figura 9 aparece a inscrição "nil sub sole novum"10, uma passagem do livro de Eclesiastes, do Antigo Testamento, que, traduzida do latim, significa "não há nada novo debaixo do sol". A expressão sugere que não existe nada realmente novo, isto é, cada ideia nova tem algum tipo de relação com o passado. Portanto, o diagrama sugere que "Libeskind imaginou a história judaica como enraizada no passado, do qual a história alemã emergiu”. (DOGAN; NERSESSIAN, 2012, p.09)
O que foi tornará a ser, o que foi feito se fará novamente; não há nada novo debaixo do sol.

Haverá algo de que se possa dizer: "Veja! Isto é novo! "? Não! Já existiu há muito tempo; bem antes da nossa época.

Ninguém se lembra dos que viveram na antiguidade, e aqueles que ainda virão tampouco serão lembrados pelos que vierem depois deles. (ECLESIASTES, capítulo 1) 


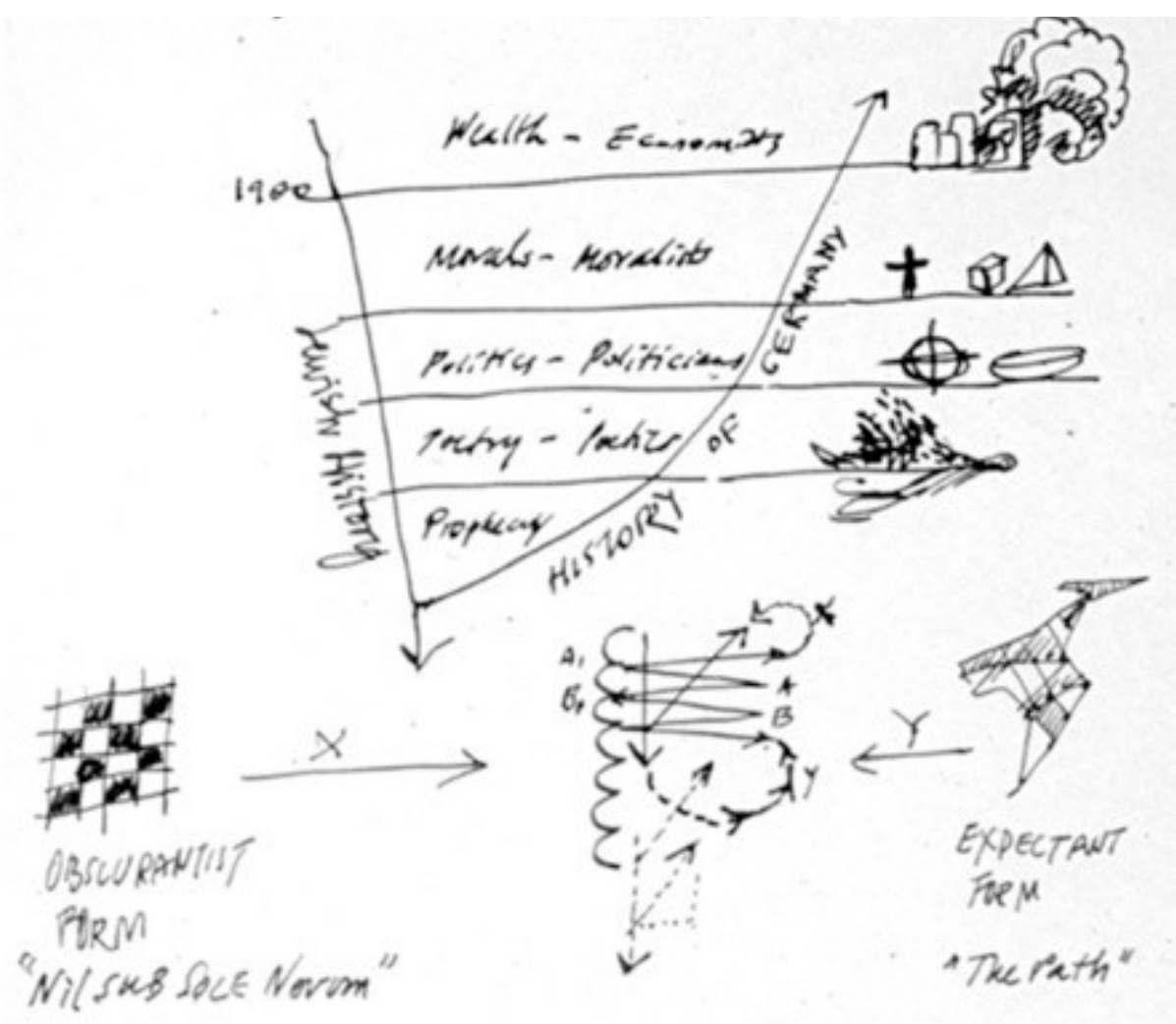

Figura 9: Diagrama da história judaica se entrecruzando à alemã.

Fonte: DOGAN, Fehmi; NERSESSIAN, Nancy J. Conceptual diagrams in creative architectural practice: the case of Daniel Libeskind's Jewish Museum. Architectural Research Quarterly, 16, 2012.

Ainda nesse mesmo desenho [Figura 9], junto à inscrição em latim, há um xadrez, que Libeskind denomina de "forma obscura", talvez como algo ordinário, cartesiano; trata-se de algo que passa despercebido, tal como a cultura judaica, que permanece obscura na Berlim contemporânea — não só pelo fato dos judeus não morarem mais lá, mas também porque grande parte de suas coleçóes foi perdida ou destruída. (DOGAN; NERSESSIAN, 2005). Na sequência, surge um traçado em zigue-zague que entrelaça as duas linhas de história e representa a "intrincada rede de interaçóes entre os habitantes de Berlim". (DOGAN; NERSESSIAN, 2012, p.09). Isso vai resultar em uma forma inusitada e nada ortogonal, a qual o arquiteto denomina de "o caminho".
Tais desenhos indicam uma exploração livre e direta entre pensamento e gesto sobre o papel, demonstrando que o objetivo do desenho à máo, neste caso, está a serviço de processos intuitivos e conceituais subjacentes à forma final do edifício.

Seguindo nessa direção interpretativa, o arquiteto não esquece os que "viveram na antiguidade", e também, ao impossibilitar o acesso aos vazios gerados pelas interseçôes do zigue-zague dentro do museu, direciona todos pelo mesmo caminho que, embora tortuoso, aponta para o futuro, para a continuidade. Logo, as indissociáveis linhas de história, entre judeus e alemães, descritas diagramaticamente de forma abstrata, vão atuar decididamente sobre o projeto resultando concretamente na primeira particularidade do projeto do Museu Judaico. 

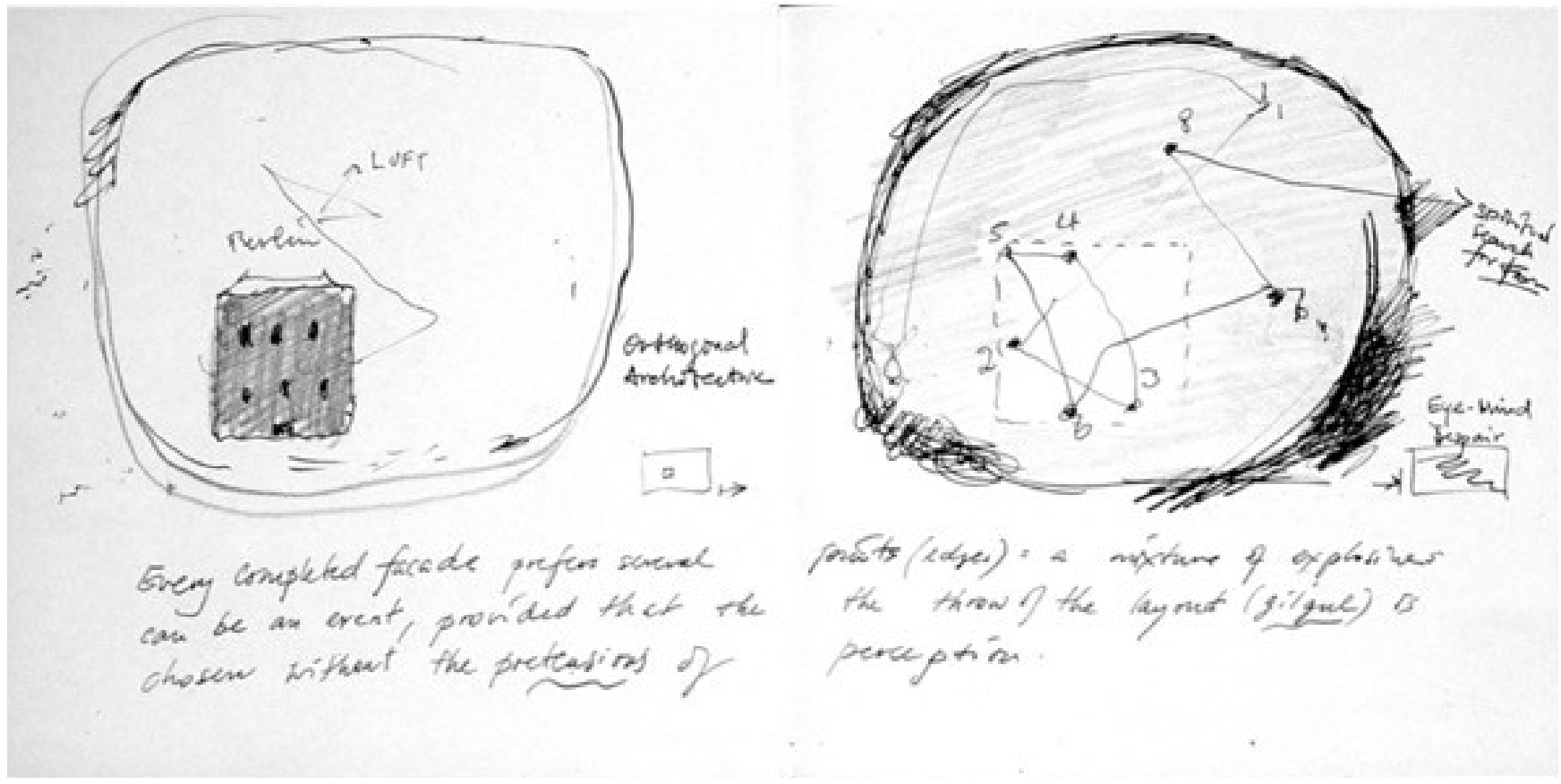

Figura 9: O céu de Berlim.

Fonte: DOGAN, Fehmi; NERSESSIAN, Nancy J. Conceptual diagrams in creative architectural practice: the case of Daniel Libeskind's Jewish Museum. Architectural Research Quarterly, 16, 2012.

No par de desenhos da figura 10, retirados do caderno de Libeskind, o croqui da esquerda, em perspectiva, mostra um ziguezague que parte de um edifício situado em terra que se projeta no céu de Berlim. $\mathrm{Na}$ página à direita, o desenho parece simular uma vista de alguém que está dentro desse mesmo prédio, mas olhando para o alto. Como se estivesse vislumbrando as estrelas, tentando encontrar uma lógica, do mesmo modo que as constelaçóes formam figuras reconhecíveis. Talvez seja o próprio arquiteto na "busca de uma ordem invisível atrás daquilo que é visível" (DOGAN; NERSESSIAN, 2012, p.07), tal qual iria fazer posteriormente sobre o mapa da cidade. Em ambos os casos, o que ele encontrou, ou até mesmo quis encontrar, foi a Estrela de David.

\section{Um museu para as vítimas}

O Holocausto pode ter provocado milhões de ausências, mas Libeskind faz questão de espalhar vestígios e pegadas pelos seus desenhos. A série de desenhos da Figura 11 consiste em exploraçóes do formato da estrela já no contexto da própria edificação - diferentemente do que se viu nos desenhos anteriores. Um símbolo que, na maioria dessas representaçóes, aparece fragmentado e dilacerado, raramente pleno.

O detalhe visto na Figura 12 já evidencia a linha da história judaica cruzando o zigue-zague da história de Berlim. Na sequência, percebe-se a evolução dessa proposta para a tridimensionalidade através de dois croquis [Figura 13]. Nestes, surgem definiçôes de volumetria, bem como alguns indícios do tratamento que seria aplicado nas fachadas. 


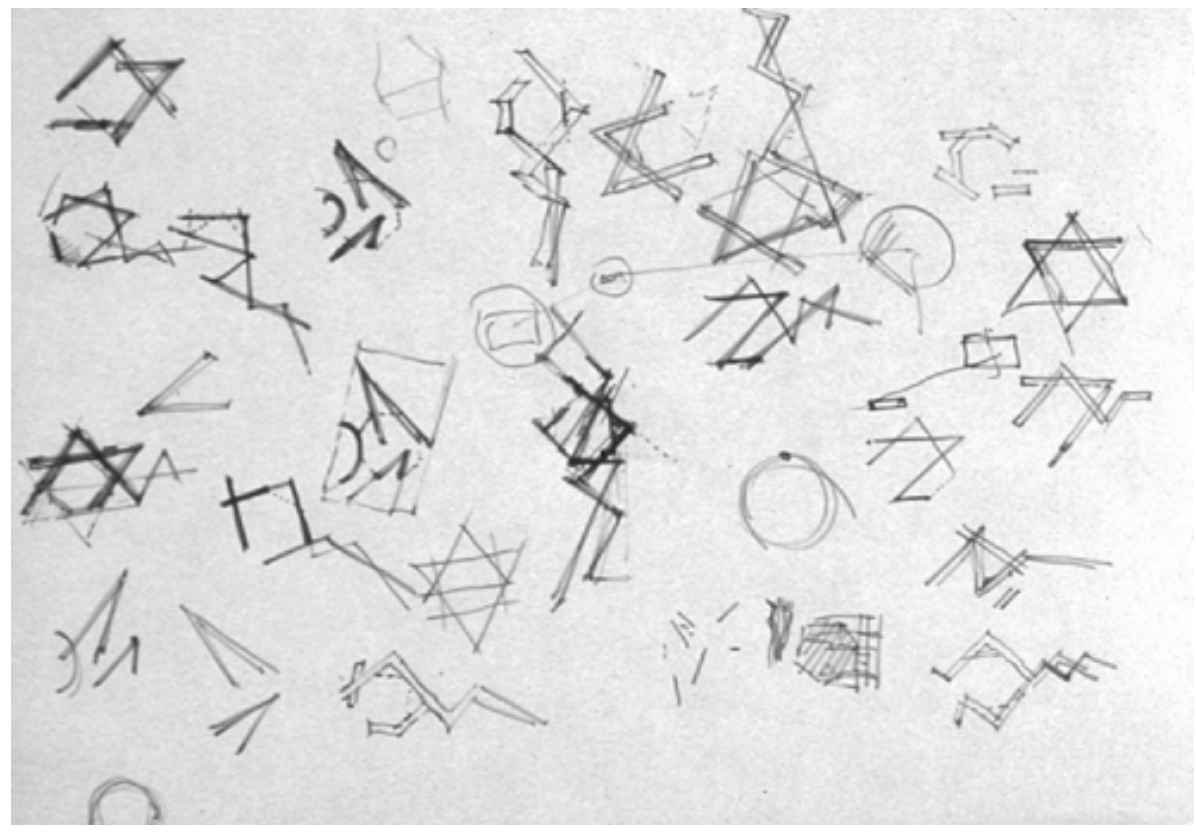

Figura 11: Estudos em torno da Estrela.

Fonte: DOGAN, Fehmi; NERSESSIAN, Nancy J. Conceptual diagrams in creative architectural practice: the case of Daniel Libeskind's Jewish Museum. Architectural Research Quarterly, 16, 2012.

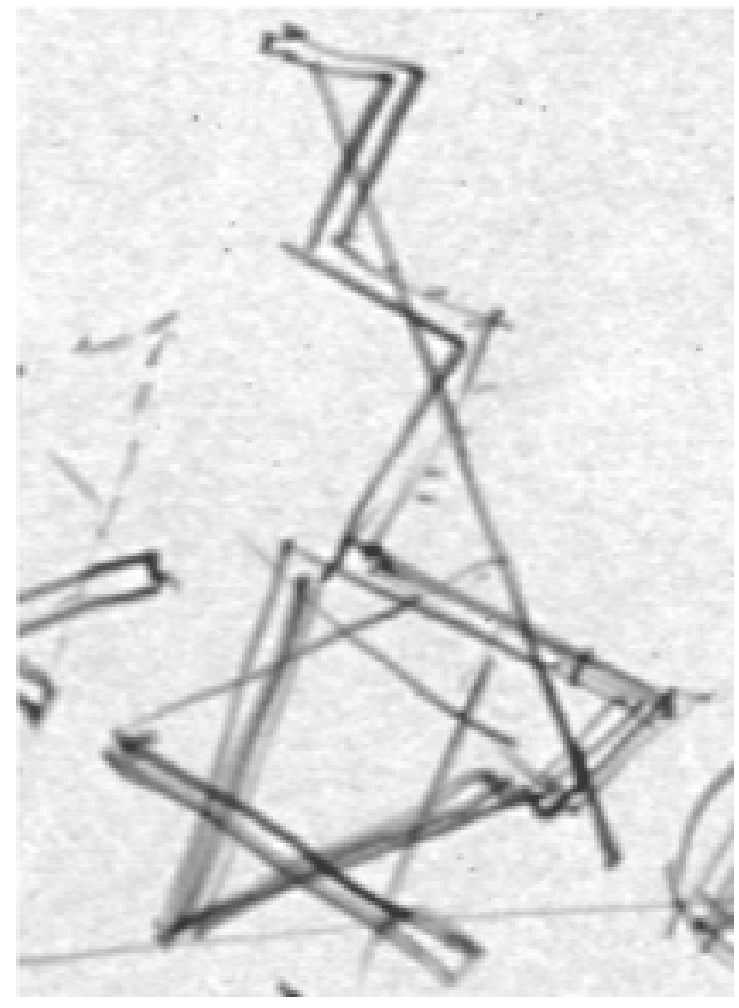

Figura 12: Detalhe.

Fonte: DOGAN, Fehmi; NERSESSIAN, Nancy J. Conceptual diagrams in creative architectural practice: the case of Daniel Libeskind's Jewish Museum. Architectural Research Quarterly, 16, 2012.
No desenho da área superior da página, a linha da história judaica, aparentemente, estava sendo estudada como uma rede de circulação acessível. Já, no croqui visto na área inferior da página, esse sistema parece ser absorvido pelo prédio em zigue-zague, algo que irá se conformar nos vazios inatingíveis. Ademais, surgem datas estratégicas relacionadas a essa trajetória de caminhos cruzados e conturbados.

A primeira, 1880, parece representar o início da perseguição aos judeus na Europa, fato que acarretou um êxodo do povo judeu nas décadas seguintes. Os anos 20 foram marcados por uma intensa migraçáo de judeus que foram se refugiar em Berlim após a Primeira Grande Guerra. Porém, em 1920, o Partido Nazista estava crescendo, e logo iria iniciar uma ímpia perseguição a esse povo. A linha do tempo é interrompida por um nome que, ao que tudo indica, pertence ao arquiteto judeu-alemão Eric Mendelsohn, que mesmo tendo servido à Alemanha na

Revista online do Departamento de Arquitetura e Urbanismo da Pontifícia Universidade Católica - 


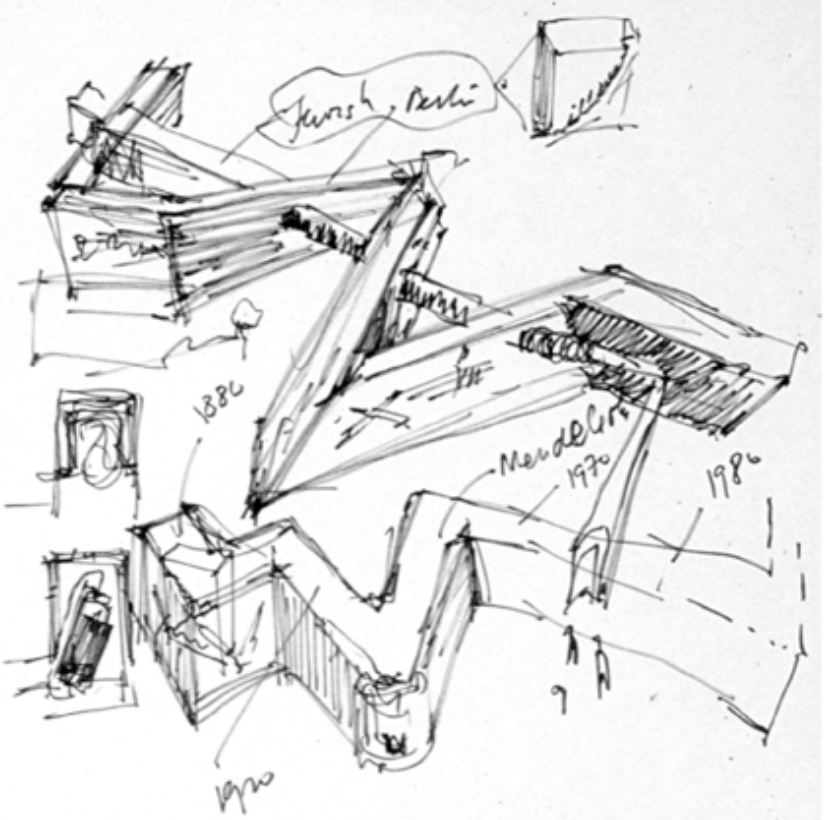

Figura 13: Croqui inicial do Museu Judaico.

Fonte: DOGAN, Fehmi; NERSESSIAN, Nancy J. Conceptual diagrams in creative architectural practice: the case of Daniel Libeskind's Jewish Museum. Architectural Research Quarterly, 16, 2012.

Primeira Guerra, foi obrigado a deixar o país devido à perseguição imposta pelo Terceiro Reich. Nos anos 70, a Alemanha estava dividida pelo Muro de Berlim, mas foi também nessa década que o Museu Judaico começou a funcionar no antigo prédio barroco.

Os registros temporais expressos no desenho vão se constituir em uma das essências do Museu já edificado, pois, a visitação ao museu é praticamente um vetor temporal de acontecimentos, isto é, uma sequência linear de eventos, paradoxalmente distribuídos pelas linhas em zigue-zague.

\section{Um livro aberto}

Planos horizontais que se articulam pelas linhas de chamada da Estrela, desenhada na base, se destacam no desenho visto na Figura 14. São como páginas de um livro, trechos da história judaica entrelaçada à história alemã. Além do mais, são testes da configuração dos trajetos subterrâneos que partem do antigo prédio barroco e levam ao Jardim do Exílio e à Torre do Holocausto. [Figura 15]. Capítulos pungentes, que surgem em evidência e descolados da volumetria principal, ou melhor, caminhos que levam à expatriação ou à morte.

Assim, esse caráter literário da obra vai se conformar no elemento derradeiro do projeto em questão.

O quarto aspecto do projeto é formado pela obra Rua de Mão Única, de Walter Benjamin. Este aspecto é incorporado na sequência contínua de sessenta seçốes ao longo do zigue-zague, cada uma das quais representa uma das "Estações da Estrela", descrita no texto de Walter Benjamin. ${ }^{11}$ (LIBESKIND, 2011, p.72, tradução nossa)

Segundo Libeskind:

É um livro estranho, um suposto guia - maravilhosamente enigmático e apocalíptico, dividido em sessenta seçóes de aforismos e reflexôes. Benjamin estava escrevendo um épico destinado a ser o seu maior trabalho quando ele fugiu de Berlim para a França em 1933. Sete anos depois, incapaz de escapar da França ocupada para a Espanha, e com seu livro ainda inacabado, cometeu suicídio para evitar a captura pela Gestapo. ${ }^{12}$ (2004, p.91, tradução nossa) 


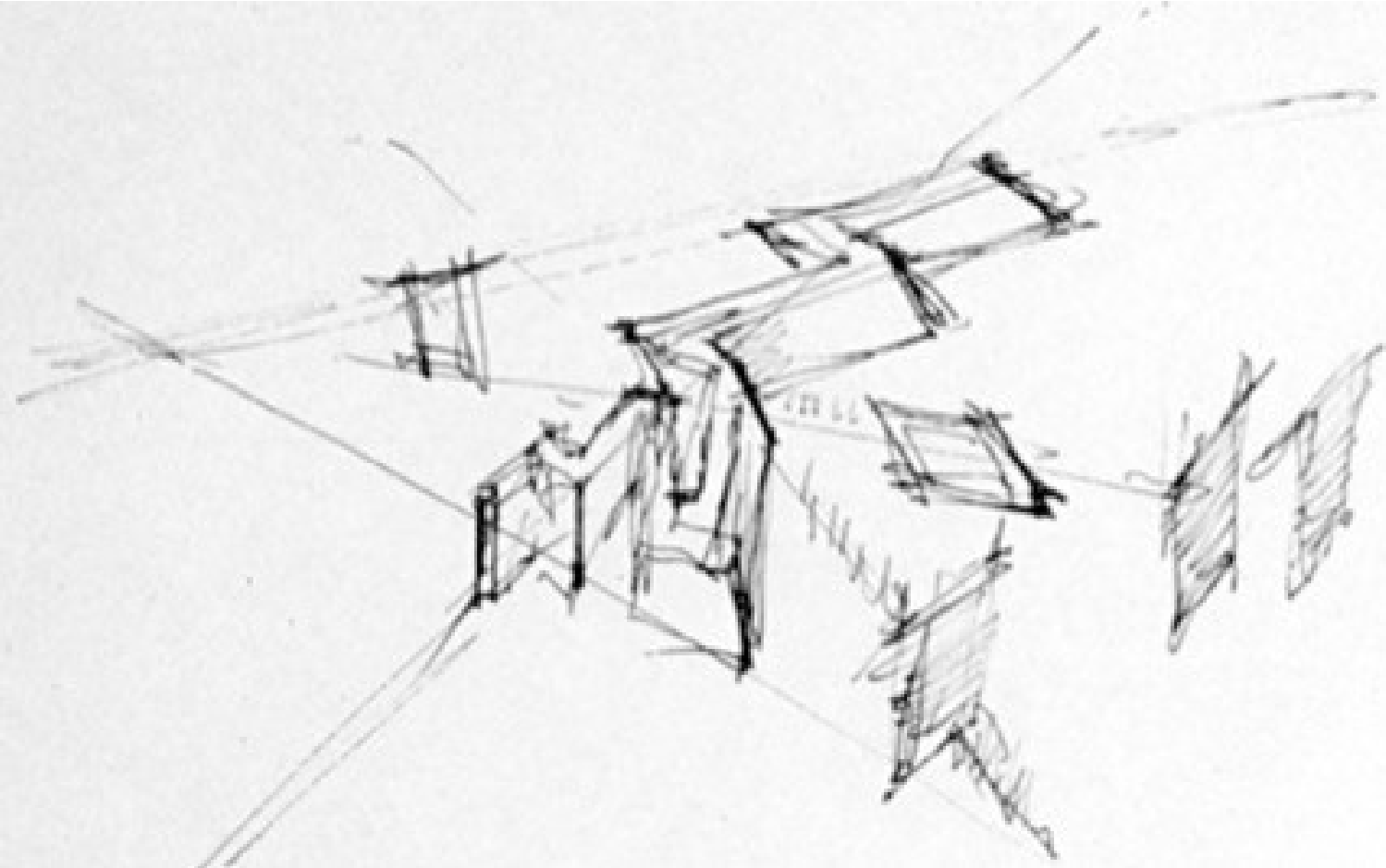

Figura 14: Croqui do Museu Judaico com "páginas" se descolando da fachada.

Fonte: DOGAN, Fehmi; NERSESSIAN, Nancy J. Conceptual diagrams in creative architectural practice: the case of Daniel Libeskind's Jewish Museum. Architectural Research Quarterly, 16, 2012.

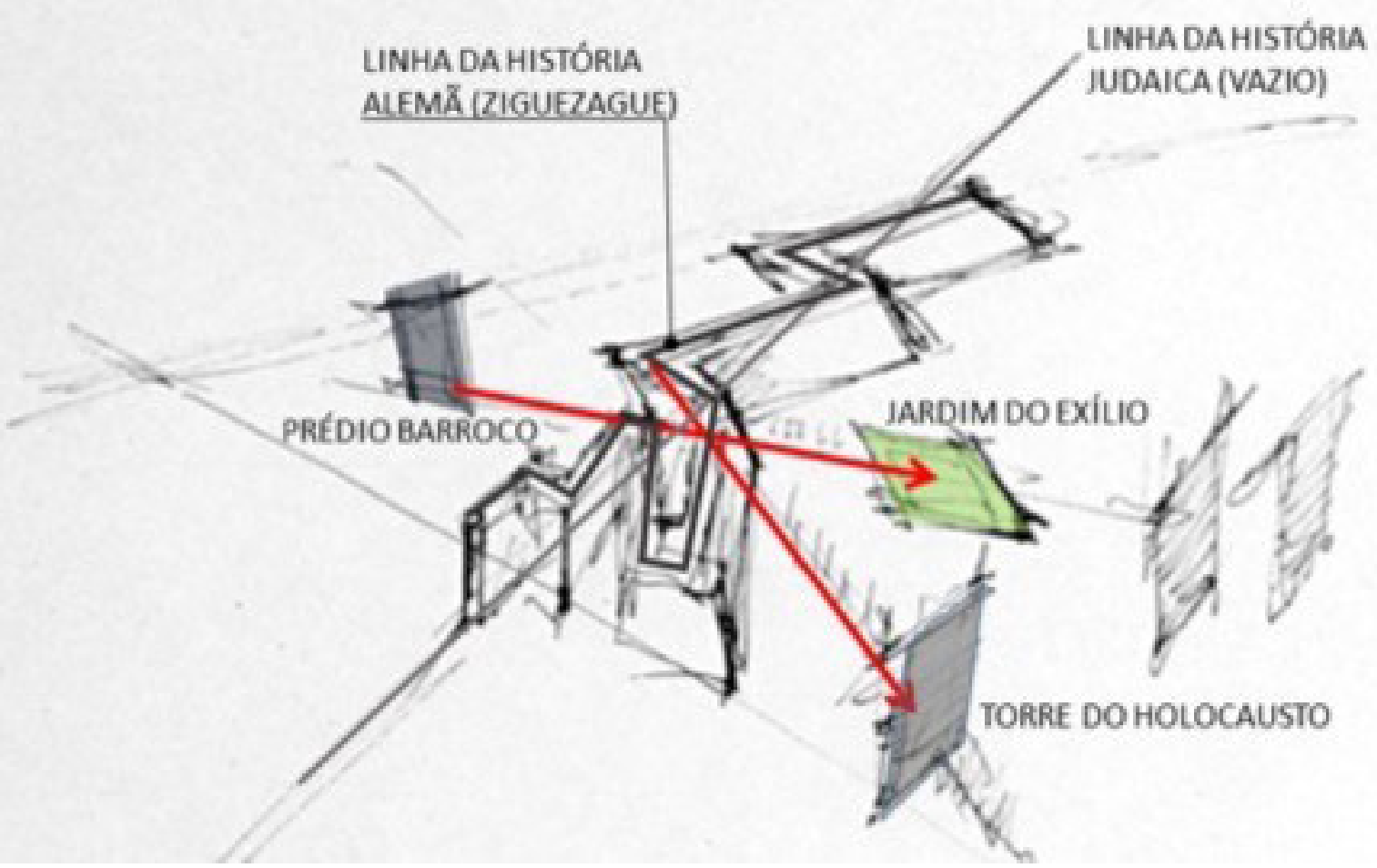

Figura 15: Fluxos subterrâneos.

Fonte: DOGAN, Fehmi; NERSESSIAN, Nancy J. Conceptual diagrams in creative architectural practice: the case of Daniel Libeskind's Jewish Museum. Architectural Research Quarterly, 16, 2012.

Revista online do Departamento de Arquitetura e Urbanismo da Pontifícia Universidade Católica -

Puc-Rio - Rio de Janeiro Brasil

Ano $3-N^{\circ} 5$ - ISSN 2446-7340 
Essa inspiração possivelmente venha de John Hejduk, já que este já havia utilizado essa obra de Benjamin no projeto Vítimas. Além do mais, a narrativa não linear de Rua de Máo Única é bem apropriada às linhas quebradas de Libeskind. A trágica biografia de Benjamin pode ser relacionada aos espaços do museu, tanto na "fuga" impossível através Jardim do Exílio, quanto na inevitável "morte" na Torre do Holocausto. O subtítulo "Fechado para a Reforma!" já prenunciava o destino do escritor.

Em sonho eu me tirava a vida com uma arma de fogo. Quando o tiro saiu, eu não acordei, mas me vi por algum tempo deitado como cadáver. Só então acordei. (BENJAMIN, 1987, p.56)

Nesse contexto, "cada um dos 60 subtítulos de Rua de Mão Única [vai estar representado em] uma sequência de 60 seçôes em zigue-zague do edifício". (BRONSTEIN, PASSARO; 2008, p.115, grifo nosso). No entanto, é algo impossível de ser percebido, a não ser pelo próprio arquiteto, como uma convenção utilizada por ele. Segundo Bronstein e Passaro:

Texto e arquitetura buscam novos significados, elaborando uma outra história, diferente da que conhecemos. Uma história paralela, que ninguém além dos próprios autores, através de um jogo intelectual, consegue conceber. (BRONSTEIN, PASSARO; 2008, p.119)

Nas Figuras 16 e 17, Libeskind gira e espelha o edifício com muita naturalidade. Eventualmente, surge o grafite vermelho como elemento de diferenciação que ressalta o caráter abstrato da especulação operada por meio dos desenhos analisados que, por sua vez, constroem uma volumetria tortuosa, praticamente indecifrável ao nível do observador.
Nesse sentido, o desenho opera em um campo fora daquele em que opera o desenho de representação de uma realidade em porvir; opera com estratégias que se concretizam, além do desenho, em um artefato que se vale de operaçóes generativas às escondidas para o resultado final. 


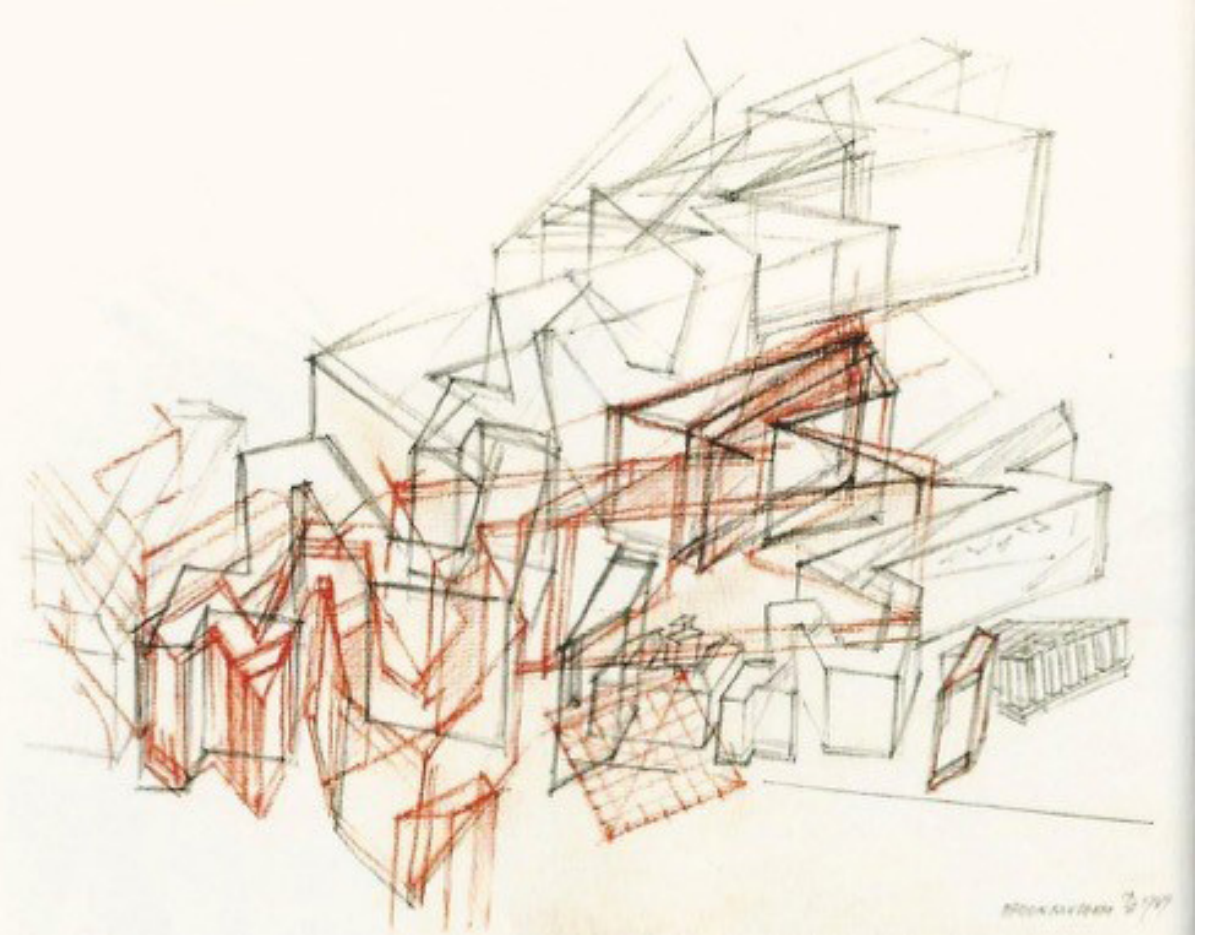

Figura 16: Croqui para o Museu Judaico.

Fonte: Daniel Libeskind: inspiration and processin architecture. Editado por Francesca Serrazanetti e Matteo Schubert. Moleskini, 2015

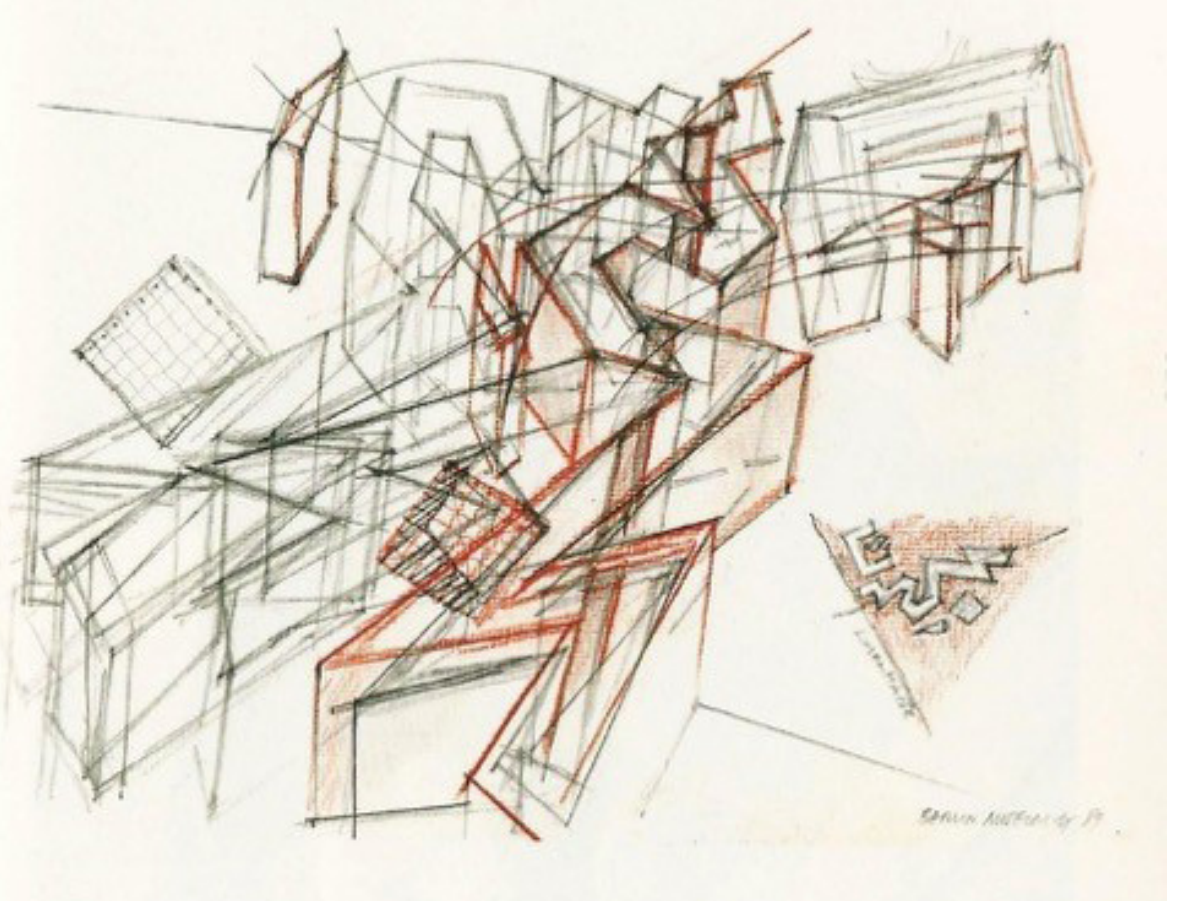

Figura 17: Croqui para o Museu Judaico.

Fonte: Daniel Libeskind: inspiration and processin architecture. Editado por Francesca Serrazanetti e Matteo Schubert. Moleskini, 2015

Revista online do Departamento de Arquitetura e Urbanismo da Pontifícia Universidade Católica Puc-Rio - Rio de Janeiro Brasil 


\section{Palavras Finais}

O desenho à mão, como meio intuitivo de operar sobre o papel decalcando impressôes iniciais ou notaçôes imprecisas de um projeto que ainda não existe em todas as suas qualidades, passa a servir claramente para novas manobras que, ao libertarem o desenho à mão de sua função restrita à visão em perspectiva como simulação da realidade, o reposicionam como ponte entre sistemas de significado mais abrangentes e o artefato que passa finalmente, e por direito, a ser representado por meios digitais.

Sob esse ponto de vista, a sequência lógica que descreve narrativas amarrando tempo e espaço sob o comando da perspectiva cônica náo se anula mas cede em nome de possibilidades náo-narrativas em que o desenho à mão funciona como ponte entre campos abstratos incompossíveis.

No caso apresentado, a narrativa de caráter arquitetônico como configuração espacial e a sequência, desvendada por meio do deslocamento no edifício construído e imaginada no projeto, cede espaço para a narrativa de caráter abstrato, conceitual ou literário. $\mathrm{O}$ artefato que resulta da construção engendrada por tais especulaçóes - no caso do Museu Judaico de Berlim o cruzamento da história judaica com a alemá, o vazio que intercepta esse cruzamento e caminhos que nascem dessa construção teórica adquire um caráter não-narrativo, quebrado, dissonante, que só é percebido em sua lógica interna por meio de desenhos transparentes e impossíveis ao olho humano, como nas perspectivas axonométricas das Figuras 16 e 17.

Esse ponto de interesse que buscamos destacar, e que recai, num primeiro momento, nos desenhos à mão, não se restringe a esse meio de expressão, mas indica um desvendar de novas possibilidades operativas de projeto que se esclarecem na interseção entre o uso de meios digitais de manufatura virtual da realidade e a possibilidade de trazer o estudo dos desenhos geradores a um foco teórico mais abrangente. 


\section{Notas de fim:}

1. Em A dúvida depois de Cézanne, o crítico de arte Paulo Sérgio Duarte discorre sobre uma nova postura cognitiva da pintura que, de acordo com Duarte, não chega a ser uma nova episteme, mas indica uma posiçáo em que "interessa reter a existência de uma ordem que estrutura, uma lógica, uma 'sintaxe visual', que não pode ser fundada somente nos aspectos puramente sensoriais, nas sensaçóes, mas que exige o investimento de uma arquitetura capaz de, rompendo com a tradição da perspectiva, não ceder exclusivamente à reduçáo do fenômeno à experiência perceptiva”.(DUARTE, 1994, p.311). Sobre as pinturas de Cézzane intituladas Mont Sainte-Victoire, Duarte nos diz que: "Mais do que seu modelo externo - a montanha - quem se transforma em motivo é o próprio processo de trabalho pictórico. Livre dos macetes da mimesis acadêmica ou de preocupaçóes metalinguísticas, a nova 'natureza' se apresenta enquanto linguagem visualmente articulada em primeiro grau". (DUARTE, 1994, p.311).

2. Drawing in architecture is not done after nature, but prior to construction; it is not so much produced by reflection on the reality outside the drawing, as productive of a reality that will end up outside the drawing. The logic of classical realism is stood on its head, and it is through this inversion that architectural drawing has obtained na enormous and largely unacknowledged generative power: by stealth.For, when I say unacknowledged, I mean unacknowledged in principles and theory. Drawings hegemony over the architectural object has never really been challenged. All that has been understood is its distance from what it represents(...). (EVANS, 1997, p.7)

3. George Didi-Huberman, diante de um dos afrescos de Fra Angelico, detém-se no fundo salpicado de tal pintura, traçando, em um salto, uma relação entre aquela pintura e as pinturas de Jackson Pollock. Assim, esclarece a paradoxal fecundidade do anacronismo: "[...] Diante do painel salpicado do século XV, o que Landino e todos os historiadores da arte foram incapazes de ver e de dar a ver Jackson Pollock - eis o anacronismo - se mostrou altamente capaz de tal ação. Se ensaio hoje rememorar o que suspendeu meu passo no corredor de San Marco, creio náo me enganar dizendo que foi uma espécie de semelhança deslocada entre o que eu descobria lá, em um convento da Renascença, e os drippings do artista americano admirado e descoberto muitos anos antes".
(DIDI-HUBERMAN, 2000, p.20, tradução nossa). Ce que, devant le pan tacheté du XVe siécle, Landinoet tous les historiens de lárt avaient été incapables de voir et de donner à voir, Jackson pollock — voilá l'anachronisme — sén est démontré hautement capable. Si jéssaie aujourd'hui de me remémorer ce qui a pu suspendre mon pas dans le corridor de San Marco, je ne crois pas me tromper em disant que ce fut une espèce de 'ressemblence déplacée' entre ce que je découvrais là, dans um couvent de la Renaissance, et les 'drippings' de lártiste américain admirés et découverts bien des années plus tôt. (DIDI-HUBERMAN, 2000, p.20)

4. Working within this problem the student begins to discover and understand the elements of architecture. Grid, frame, post, beam, panel, center, periphery, field, edge, line, plane, volume, extension, compression, tension, shear, etc. The student begins to probe the meaning of plan, elevation, section, and details. He learns to draw. He begins to comprehend the relationships between two-dimensional drawings, axonometric projections, and three-dimensional (model) form. The student studies and draws his scheme in plan and in axonometric, and searches out the threedimensional implications in the model. An understanding of the elements is revealed - an idea of fabrication emerges. (HEJDUK, 1971, p.7)

5. A Cube problem is not unique to a particular architectural school; it is some what universal; its staying power appears to profess that it will still be used for some time in the future as a didactic problem. The interest lies in how it is viewed. It is typical that the architect is given a program from which an object emerges; it does seem possible that perhaps the opposite could occur. That is, given an object, perhaps a program could emerge. This is one of the premises stated upon presentation of the Cube Problem.(HEJDUK, 1971, p.99)

6. Frontality, suppression of depth, contracting of space, definition of light sources, tipping forward of objects, restricted palette, oblique and rectilinear grids, and propensities toward peripheric development are all characteristics of analytical cubism. (ROWE; SLUTZKY, 1963, p. 46)

7. "Do a building in the intention of Juan Gris". (...) Most students reject it outright - some become interested in its implications. A few, using it as a foundation for movement, produce a work. For those who do choose this problem, a very thorough analysis into the generating ideas within the 
paintings of Juan Gris and within the work of the Cubists - Picasso, Braque, and Leger - is made.Relationships between the ideas and work of architects and painters are discovered. An understanding of the organic links is revealed. The pursuit is more than just an historical analysis - for the student produces a work. He finds that the initial statement of the problem launches him into the world of re-creation and finally creation. This, of course, could be the illusionary view of the teacher - the student's reality may be elsewhere. The above does depend on the belief that 'Uuan Gris' is important to architects and to the issues of today. (HEJDUK, 1971, p.163)

8. The site is the new-old center of Berlin on Lindenstrasse next to the distinguished Kollegienhaus, the former Baroque Prussian courthouse. At the same time that there was this actual visible site, I felt that there was an invisible matrix of connections, a connection of relationships between figures of Germans and Jews. Certain people, workers, writers, composers, artists, scientists, and poets formed the link between Jewish tradition and German culture. I found this connection, and I plotted an irrational matrix wich would yield references to the emblems of a compressed and distorted star - the yellow star that was so frequently worn by jews on this very site. This is the first aspect of the project. (LIBESKIND, 2011, p.71).

9. O concurso para o Museu Judaico de Berlim foi lançado em 1988, mas foi julgado em 1999. Libeskind recebe o primeiro prêmio e as obras são concluídas em 1999.

10. A expressão correta é "nihil sub sole novum". Talvez tenha ocorrido um erro de grafia, ou uma abreviação por parte de Libeskind.

11. The fourth aspect of the project is formed by Walter Benjamin's One-Way Street. This aspect is incorporated into the continuous sequence of sixty sections along the zigzag, each of wich represents one of the "Stations of the Star", described in the text of Walter Benjamin.(LIBESKIND, 2011, p.72)

12. It's a strange book, a supposed guidebook - marvelously enigmatic and apocalyptic, divided into sixty sections of aphorisms and ruminations. Benjamin was writing an epic reported to be his greatest work when he fled Berlin for France in 1933. Seven years later, unable to escape occupied France for Spain, and with his book still unfinished, he committed suicide to avoid capture by the Gestapo.(LIBESKIND, 2004, p.91)

\section{Referências Bibliográficas:}

AMORIM, Jonas Delecave. John Hejduk e os mundos da Cooper Union. Revista Prumo, [S.l.], v. 2, n. 2, p. 8, jan. 2017. ISSN 2446-7340. Disponível em: <http:// periodicos.puc-rio.br/index.php/revistaprumo/article/ view/164>. Acesso em: 08 apr. 2018.

BRONSTEIN, Laís; PASSARO, Martin. Rua de mão dupla: leituras berlinenses de John Hejduk e Daniel Libeskind. Arqtexto 13. Porto Alegre: PROPAR, 2008.

. As coleçôes de Aldo Rossi e John

Hejduk. I ENANPARQ. Rio de Janeiro, 2010.

BENJAMIN, Walter. Rua de mão única. São Paulo: Brasiliense, 1987.

DID-HUBERMAN, George. Devant le temps: histoire de l'art et anachronisme des images. Paris: Les Editions des Minuits, 2000.

DOGAN, Fehmi; NERSESSIAN, Nancy J. Conceptual diagrams in creative architectural practice: the case of Daniel Libeskind's Jewish Museum. Architectural Reaserach Quarterly, 16, 2012.

https://www.semanticscholar.org/paper/ConceptualDiagrams-in-Creative-Architectural-Prac-Dogan-Nersess ian/91fc878ff1bd25efbbc7082aff01dcdd5597d3e1

Design problem solving with conceptual diagrams. Proceedings of the cognitive science society, 2005.

DUARTE, Paulo Sérgio. A dúvida depois de Cézzane. In: NOVAES, Adauto (Org.). Artepensamento. São Paulo: Companhia das Letras, 2000.

EISENMAN, Peter. Diagram diaries. New York, NY. Universe, 1999.

EVANS, Robin. Translation from drawing to building. AA Files, no. 12, 1986, pp. 3-18. www.jstor.org/ stable/29543512.

HAYS, Michael. Architectural theory since 1968. New York: Columbia, 1998.

HEJDUK, John. The nine square problem. In: Education of na architect. a point of view. An exhibition by the Cooper Union School of Art \& Architecture at The Museum of Modern Art, New York City, november, 
1971. https://www.moma.org/documents/moma catalogue_2648_300298971.pdf

The cube problem. In: Education of na architect. a point of view. An exhibition by the Cooper Union School of Art \& Architecture at The Museum of Modern Art, New York City, november, 1971. https://www.moma.org/documents/moma catalogue_2648_300298971.pdf

. The Juan Gris problem. In: Education of na architect: a point of view. An exhibition by the Cooper Union School of Art \& Architecture at The Museum of Modern Art, New York City, november, 1971. https://www.moma.org/documents/moma catalogue_2648_300298971.pdf

LEVENE, Richard; CECILIA, Fernando Marquez. Daniel Libeskind 1987-1996. In: El Croquis 80. Madrid: El croquis editorial, 1996.

LIBESKIND, Daniel. Breaking ground. New York: Riverhead books, 2004.

Rizzoli, 2000. . Space of encounter. New York:

MONTANER, Josep Maria. Del diagrama a las experiencias, hacia uma arquitectura de acción. Barcelona: Editorial Gustavo Gili, 2014.

NESBIT, Kate. Uma nova agenda para a arquitetura: antologia teórica (1965-1995). São Paulo: Cosac Naify, 2006.

PATERSON, Mark. The senses of touch: haptics, affects, and technologies. Oxford: BERG, 2007.

RECENA, Maria Paula. Notaçôes arquitetônicas: diagramas, coreografias, composiçôes. Tese de Doutorado. PROPAR UFRGS, 2013.

ROWE, Colin; SLAVUTZKY, Robert. Transparency: literal and phenomenal. Perspecta, Vol. 08, 1963.

SERRAZANATTI, Francesca; SCHUBERT, Matteo (Ed.). Daniel Libeskind: inspiration and process in architecture. Moleskini, 2015. 